\title{
In Response: From Manchikanti et al
}

We appreciate the lengthy letter by Chou entitled "Critiquing the Critiques." At the outset, the letter reminded us of an exchange between Bogduk and Carragee in 2007 (1) criticizing each other - Bogduk claiming that Carragee et al utilized sophistry to discredit the study, whereas Carragee described Bogduk's argument as "inflated albeit entertaining rhetoric". Bogduk elaborated that the defense to sophistry is to inform the listeners of the fallacy of the argument, and to point out the opposite when it applies. In contrast, Carragee borrows Aristotle's caution in The Art of Rhetoric, that when one hears bombastic and exaggerated styles of argument, the substance is likely deficient (2). Here, it appears that Chou's argument could qualify for sophistry, and the art of rhetoric by rehashing the same arguments over and over again while leaving the substance out.

ASIPP rigorously supports peer-reviewed and bias free research including evidence synthesis, as well as government funding of such efforts. The criticism is extremely important, especially when the work is generously supported by taxpayer funds or even membership dues as in the case of the American Pain Society (APS). It appears that Chou, instead of aiming at imag- ined inappropriate issues should focus and concern himself with valid points raised in the critique. Further, it appears Chou is begging for shielding for funding from government grants as well as membership dues from the societies from open scientific critical reviews by concerned professional societies, which is grossly improper.

Physicians specializing in methodology, either working with the government or insurers or guideline developers, have a right to claim the supremacy of their methodology - at least in their own minds. However, they have a responsibility to understand the flaws in their vaunted methodology. Consequently, it is difficult to understand the wisdom of recommending or not recommending techniques without understanding them.

Further, it has become quite a bit of a phenomenon and tradition for the experts who disagree with clinicians to act as victims. However, history shows it to be different. For example, if we look at the demise of Agency for Health Care Policy and Research (AHCPR) with its $\$ 75$ million expenditures per guideline and proposed expenses of $\$ 200,000$ to $\$ 300,000$ for each systematic review, it would appear that this network 
of specialists had as its major goal to show that nothing works $(3,4)$.

It is very perplexing to note that intricacies of evidence-based medicine (EBM) and methodology continues to change based on the philosophy of sponsoring agencies and insurers. We would welcome any type of proof that shows the evidence created by Chou and others is in fact based on evidence and that it improves patient care. It is extremely easy for methodologists to repeatedly tell clinicians that if they want to provide evidence that injection therapy is effective in specific subgroups of patients with subacute or chronic pain, they should conduct well-designed and randomized clinical trials (RCTs) with homogenous patient populations, a clear target condition, a clear-cut treatment rationale, and a sufficiently long follow-up period $(5,6)$. We clinicians then work hard to follow this, only to find that the methodologists then create criteria to discredit the same methodology they have been preaching.

With reference to West et al (7), we are at a loss as to why the Agency for Healthcare Research and Quality (AHRQ) would spend hundreds of thousands or even millions of dollars evaluating the quality criteria developed by others and then not provide guidance. Is it not appropriate to use the quality rating systems which have been appropriately looked at and summarized? Whether they are designed to be used to rate the study quality themselves or not, we fail to see the relevance and importance. Obviously this critical analysis should have done something and provided the readership with some guidance.

The next comment relates to the weighted scoring system for scoring the criteria included in the Cochrane Back Review Group (CRBG). Chou claims we said that a weighted methodology for rating RCTs is superior to unweighted methodologies. However, the word superior was never used in our manuscript. In addition, neither the weighted methodology nor unweighted methodologies have been supported by any empirical data or validation studies (8-15). Coincidentally, the overall quality of Cochrane systematic reviews was rated as fair to good (16). Further, to be uniform, we utilized the scoring system by Chou and Huffman (1719), which has been used in multiple publications. They also chose to avoid citing manuscripts if they were favorable to clinicians, even one authored by Rubinstein and van Tulder (20). Rubinstein and van Tulder (20), in a best evidence review of diagnostic procedures for neck and low back pain, concluded that there was strong evidence for the diagnostic accuracy of facet joint blocks in evaluating spinal pain. Yet Chou and others claim that due to the lack of a gold standard, facet joint pain cannot be treated.

The next involves the methodologic quality assessment of systematic reviews. Again, Chou mentions that the final score is not based on simply adding the number of criteria that are met; rather it is based on the assessment of the type and severity of methodological flaws. Once again, it is essential to mold the result as they would like to rather than follow a methodology. Then they provide the explanation that if a systematic review combined studies inappropriately, the scoring instructions are that it is likely to have major flaws. However, this has no relevance to the total scoring. Then they continue to bolster their argument by invoking in their methods section that their sole source of evidence for evaluating efficacy was randomized, placebo, or sham-controlled trials.

We do not doubt Chou's extensive experience with the United States Preventive Services Task Force (USPSTF) methods, we only doubt the application of those methodologies to clinical situations. In fact, David Eddy and multiple other speakers utilized the criteria utilized in American Society of Interventional Pain Physicians' (ASIPP) guidelines rather than those Chou has recommended. The issue is related to using them in an unbiased fashion rather than continuing to repeat them and using them with bias and subjectivity and calling everything else biased and subjective.

The above explanations address some of the issues, but the lack of transparency, accountability, consistency, and independence are still troubling. Leaving numerous deficiencies described in the critique aside, Chou jumps into a study by Mathews et al (21) which was always excluded in ASIPP reviews. Further, we have not claimed that lack of placebo control was poor quality; however, we did describe the short duration of follow-up and use of high volume injections as exclusion criteria or poor quality as Chou mentions. These might not be associated with bias per se in the methodological world, but they are associated with insurmountable clinical irrelevance in the clinical arena. It is important to understand that the study by Mathews et al (21) was included in 4 of the Cochrane reviews of injection therapy $(8-10,22)$, with a composite score of 67 of 100 for the manuscript which was published in 1987. By any criteria, 67 of 100 would be considered appropriate when 8 of the 11 criteria are met. 
The next issue relates to caudal epidural injections (23). Chou ignores the fact that these patients, by selection criteria, already failed to improve with caudal epidural injections. Thus, if he wishes to utilize these for caudal epidural injections, he should mention the entire inclusion criteria, and also show that caudal epidural injections are not effective in patients who failed previously to respond to other caudal epidural injections. Then he provides a reinforcement tool, that "A basic principle of conducting systematic reviews is to follow the methods laid out for including and excluding studies, in order to remove subjective bias in selection of studies" Which applies to everyone, but, Chou and other methodologists. Chou and Huffman misinterpreted the evidence on adhesiolysis with lack of proper review of so-called placebo effect (23). If the reviewers would look carefully, this study did show placebo or positive effect at one month with significant pain relief of $50 \%$.

Dashfield et al (24) compared caudal epidural injections with spinal endoscopic adhesiolysis, which is not indicated in patients without previous surgery or lumbar epidural fibrosis; yet Chou ignored or decided not to use this study for caudal epidural injections. This study was performed utilizing fluoroscopy and also had a rating of 7 of 11 by APS-AAPM methodologic quality assessment. Further, Chou also has not utilized Ackerman and Ahmad (25) in their evaluation of transforaminal epidural injections. However, they utilized a very low quality study by Zahaar (26). Chou and Huffman also missed the spinal endoscopic adhesiolysis manuscript which was published a long time before the review was conducted (27). It also appears that Chou and Huffman might have purposefully excluded the critical analysis of the American College of Occupational and Environmental Medicine (ACOEM) guidelines (28).

With regards to radiofrequency neurotomy, it is very clear that Chou does not understand clinical significance, as he does not think there is any value for properly positioning a radiofrequency cannula. For the record, the manuscript by Tekin et al (29) did not meet the inclusion criteria by ASIPP (30). Even then, when comparing 3 active control techniques, the authors showed significant decreases from the baseline in all 3 groups, including local anesthetic injection or control, pulsed radiofrequency, and conventional radiofrequency neurotomy. However, the differences were higher in the conventional radiofrequency group with baseline VAS of $6.5 \pm 1.5$ compared to at one year, 2.4 \pm 1 .1. None of the other groups showed $50 \%$ improvement. Certainly creative statistics can be presented to fit specific needs. With reference to Nath et al (31), Chou et al continued to refuse to admit the errors in their evaluation, now resorting to criticizing the randomization method, even though it was appropriate. Neither Bogduk (32), Nath et al (31), Datta et al (30), nor us, feel that has made any significant difference. Chou and Huffman (17) originally reported the final outcome scores in both groups were identical and there was no change in low back pain. This is in contrast to the manuscript which showed clear and distinct differences between both groups in all aspects of pain and quality of life variables. Chou and Huffman also missed the fundamental and basic fact that it was an active control study with needle placement, as well as local anesthetic injection over the nerve. The recent criticism from Chou has been that "the sham control group (which had higher baseline scores) had greater potential to experience improvement from baseline." This criticism is not justified due to lack of a placebo group. Of the multiple other studies Chou and Huffman have included, Van Wijk et al (33), and multiple other studies did not meet inclusion criteria by others due to numerous deficiencies $(29,33-37)$. Chou continues to deny the fact that these procedures were not performed appropriately. Of most interest is Leclaire et al (34) which invited criticism because it failed to define the study population and had inappropriate diagnostic criteria with a single intraarticular injection with inappropriate evaluation of response $(50 \%$ relief for one day any time during the week) to identify patients for radiofrequency neurotomy. Finally, there was no placebo control. Interestingly enough, in response to Gauci's (38) request, Leclaire et al (39) acknowledged multiple deficiencies. They described that their study used an invalidated and dated approach $(30,40)$, and acknowledged the value of controlled local anesthetic blocks, false-positive results and technical aspects - which were all lacking (39). It is very interesting that Leclaire is the second author of the manuscript published by Carette et al (41), which is considered as a standard for negative response to treatment and also for positive response with sodium chloride solution injected into a closed space. Other studies including Van Wijk (33) also had multiple deficiencies (42) of their own results.

On the diagnostic accuracy of invasive diagnostic techniques, we have provided in detail various criterion standards including long-term follow-up, which is 
utilized in diagnostic facet joint nerve blocks $(43,44)$. Further, Chou does not mind misquoting us that we do not dispute that there is little evidence showing that provocative discography or facet joint blocks improve clinical outcomes. Further, he adds a very poorly performed study (45) which presents issues with regard to scientific methodology and the practice of interventional pain management. In fact, a reader would assume that double blocks are specific, cost-effective, and recommended (45). Cohen et al (45) started with an inadequate sample and provided statements implying that repeat blocks continue to increase false-positives. This has not been shown to be true in multiple studies using the criterion standard of $80 \%$ pain relief with dual comparative blocks and the ability to perform previously painful movements, with a sustained diagnosis of facet joint pain after 2 years in $90 \%$ of the patients $(43,44)$.

Chou and Huffman (17) also inappropriately included Birkenmaier's study (46) while excluding Rubinstein and van Tulder's best evidence review (20). The Birkenmaier study (46) is not only of poor quality, but has not met any inclusion criteria for a diagnostic accuracy study. It essentially compared 2 uncontrolled procedures. They utilized high concentrations of bupivacaine, $0.5 \%$, and volumes higher than $1 \mathrm{~mL}$. Even so, Birkenmaier et al (46) showed that patients who had been selected by medial branch blocks had better pain relief than did patients who had been diagnosed using pericapsular block with statistical significance noted at 6 weeks and 3 months. They also concluded that if serial controlled blocks cannot be used, lumbar facet joint pain remains a diagnostic dilemma.

The misunderstandings or lack of understanding of placebo continues to be a major issue. There are numerous difficulties related to placebo groups and interventional techniques. An active control study utilizing local anesthetic is not a placebo, even though Chou, Nelemans and Staal with their self-appointed authority arbitrarily converted it into a placebo $(10,17,22)$.

By definition, the placebo effect is a physiological and/or psychological reaction to an inactive substance or an inactive procedure. Consequently, placebo effect represents a key interphase between physiology, psychology, and patient care (47-49). It has been shown that the magnitude of placebo analgesia is highly variable (50). Consequently, understanding predictors of placebo analgesia is important, as treatment for chronic pain can benefit from clinically meaningful placebo effects. Similarly, it is essential for clinicians and methodologists to understand nocebo effects.

In contrast to placebo, nocebo represents a phenomenon opposite that of placebo analgesia, characteristically considered to be a worsening or consistent lack of change of symptoms after the administration of some agent known to be effective - hyperalgesia $(48,49)$. However, nocebo effects in interventional pain management have not been carefully distinguished from drug-induced hyperalgesia, tachyphylaxis, tolerance, and/or progression of the underlying organic pathology causing increased pain and diminished sensitivity to a particular pharmacologic agent or procedure.

It has been demonstrated that multiple personality variables, including optimism and pessimism of not only the patient desire for reduction of pain, but also the referring physician, family, and the investigators themselves, can produce or alter placebo analgesia, or even induce a nocebo effect (51-55). Thus, one can argue that a treatment's failure is a nocebo effect in a controlled situation, the opposite of the placebo effect. For example, in a study in patients undergoing interventional procedures, sodium chloride solution, midazolam, and fentanyl produced placebo effects in $13 \%$ to $15 \%, 15 \%$ to $20 \%$, and $18 \%$ to $30 \%$ of the patients respectively (48). However, a nocebo effect was seen in $5 \%$ to $8 \%$ of the patients in the sodium chloride group, $8 \%$ of the patients in the midazolam group, and $3 \%$ to $8 \%$ of the patients in the fentanyl group. Consequently, it is essential to focus on not only the methodological aspects, but also other aspects, wherein positive and negative effects might be seen either with placebo or active agents in $13 \%$ to $30 \%$ of patients (48).

Designing a placebo study in interventional techniques is an extremely difficult venture. Many believe that comparing the impact of an intervention with the natural course of the disease in a randomized, blinded fashion can only be achieved when the comparator group receives a placebo. This placebo, in the case of interventional treatment, would be a sham intervention, and represents the first obstacle for RCTs in interventional pain management. Considering that interventional pain management techniques are only offered when conservative treatment fails, researchers face a patient population that has a highly pronounced wish for improvement and is often reluctant to accept the potential receipt of a placebo therapy. This results in a high rate of patients' refusal to par- 
ticipate in a study and subsequent withdrawals if they do participate - an apparent nocebo effect. The placebo effect will not actually reveal the true effect of the lack of treatment since all patients who are suffering with chronic pain are not enrolled in the study, and are not receiving the same attention, evaluation, explanation, and so-called placebo treatment. Finally, one must design a TRUE placebo study.

Very few studies have applied true placebo or so-called sham interventions. Many of those claiming to be placebo-controlled are actually active interventions. True placebo would only be injection of an inactive agent into an inactive location away from the epidural space or facet joint nerves, or facet joints themselves. Even the injections of sodium chloride solution and dextrose have been shown to yield different results (56). The experimental and clinical findings from the investigations of the electrophysiological effects of $0.9 \%$ sodium chloride and dextrose $5 \%$ in water solution have illustrated multiple variations of neural stimulation. The potential inaccuracy created by $0.9 \%$ sodium chloride solution versus $5 \%$ dextrose has been described in the literature (56-58). Further, injection of sodium chloride either into the disc, facet joint, or paraspinal muscles produces similar, yet variable results $(58,59)$. There are also studies showing the lack of inertness of sodium chloride solution when injected into a closed space, and sodium chloride has been injected to treat low back pain and sciatica (60).

In addition to the injection of placebo, placement of the needle itself and injection of any solution with adhesiolysis effects in addition to the neurolytic effects of the needle and various solutions injected, along with mechanical pressure, and dilution of inflammatory substances, also play a substantial role in understanding the placebo effect or its lack thereof.

Clinical aspects, as well as placebo and nocebo, have to be taken into consideration if local anesthetic is considered to be a placebo, or even if the placebo actually helps. Is it worthwhile to provide patients with such a placebo treatment for them to improve? Otherwise, the patients with long-term chronic pain might continue to suffer. Also, when evaluating a placebo effect, one should consider the role of repeat interventions over a period of as long a time as 2 years or so with continued positive results in a high percentage of the patients similar to the other intervention.

Local anesthetics also have been described and proven to provide short and long-term symptomatic relief based on various mechanisms (61-68), including suppression of nociceptive discharge, the block of axonal transport, the blockade of the sympathetic reflex arc, blockade of sensitization, anti-inflammatory effect, and axonal transport blockade of nerve fibers. Further, no additional benefit was demonstrated by using corticosteroids in rat experimentation with nerve root infiltration with either local anesthetic alone, or with local anesthetic and steroids (68).

Chou states that we question the integrity of the APS review and guideline which is unjustified and uncalled for. We believe that it is for the public to decide. We still need clarification as to why so many errors are present as per Chou's explanation with the inclusion of the American Academy of Pain Medicine (AAPM) and the American College of Physicians (ACP). The second issue relates to the funding - why is it so secretive, how much funding was provided, and of that funding, how much was received by Chou and Huffman? It seems that these are the only 2 who have received funding and worked on the manuscript. Chou has failed to show who was in the working group, how many of them left, and the reasons why they left.

Finally, doing serious work that Dr. Chou claims to do for better patient care and the health and welfare of the public in a cost effective manner should earn him respect by the recipients of such care and the providers but the result of his involvement raises serious questions about his intentions, and agenda in secrecy. The bottom line is just don't love the truth and hate the facts. Once again using Carragee's approach, we are also reminded of the American legal aphorism: "When you have the facts on your side, pound the facts; when you have the law on your side, pound the law; if you have neither the facts nor the law, pound the table."

We believe Dr. Chou is pounding the table.

Laxmaiah Manchikanti, M.D.

2831 Lone Oak Road

Paducah, Kentucky 42003

E-mail: drlm@thepainmd.com

Sanjeeva Gupta, MD

Specialist in Pain Management

Dept. of Anaesthetics and Pain Management

Bradford Royal Infirmary

Bradford Teaching Hospitals

NHS Foundation Trust

Bradford BD9 6RJ

UK

E-mail: sgupta6502@aol.com 
Ramsin Benyamin, MD

Millennium Pain Center

1015 S. Mercer

Bloomington, IL 61701

E-mail: ramsinbenyamin@yahoo.com

Rajesh Munglani, MD

Consultant in Pain Management

BUPA Cambridge Lea Hospital

30 New Road

Impington

Cambridge CB4 9EL

E-mail: rajeshmunglani@gmail.com

Sukdeb Datta, MD

Vanderbilt University

Interventional Pain Program

Nashville TN 37027
Board Member, American Society of

Interventional Pain Physicians

E-mail: sukdeb@hotmail.com

Joshua A Hirsch, MD

Harvard Medical School

Boston, MA 02114

Board Member, American Society of

Interventional Pain Physicians

E-mail: jahirsch@partners.org

Stephen P. Ward, MD, FRCA, FFPMRCA

Brighton and Sussex University Hospitals

NHS Trust

RH16 4EX

UK

E-mail: stephen.ward@bsuh.nhs.uk

\section{References}

1. Bogduk N. In defense of King et al: The validity of manual examination in assessing patients with neck pain. Spine J 2007; 7:749-752; author reply (Carragee EJ) $752-753$.

2. Aristotle. The art of rhetoric. [LarsonTancred HC, translator]. Penquin Classic, New York, NY, 1991.

3. Gonzalez EG, Materson RS. The guidelines, the controversy, the book. In Gonzalez ER, Materson RS (eds). The Nonsurgical Management of Acute Low Back Pain. Demos Vermande, New York, 1997, pp 1-4.

4. Deyo RA, Psaty BM, Simon G, Wagner $\mathrm{EH}$, Omenn GS. The messenger under attack - intimidation of researchers by special-interest groups. $N$ Engl J Med 1997; 336:1176-1180.

5. Van Boxem K, Van Zundert J, van Kleef $M$. Letter to the Editor Re: Staal JB, de $B i e$, de Vet HC, et al. Injection therapy for subacute and chronic low-back pain. Cochrane Database Syst Rev 2008: CDoo1824. Spine 34:1628-1629.

6. Interventional pain management in the era of evidence-based medicine and comparative effectiveness research. ASIPP News, Summer 2010

7. West S, King V, Carey TS, Lohr KN, McKoy N, Sutton SF, Lux L. Systems to Rate the Strength of Scientific Evidence. Evidence Report/Technology Assessment No. 47. AHRQ Publication No. 02-E016.
Rockville, MD: Agency for Healthcare Research and Quality, 2002.

8. Koes BW, Scholten RJ, Mens JM, Bouter LM. Efficacy of epidural steroid injections for low-back pain and sciatica: A systematic review of randomized clinical trials. Pain 1995; 63:279-288.

9. Koes BW, Scholten RJ, Mens JMA, Bouter LM. Epidural steroid injections for low back pain and sciatica. An updated systematic review of randomized clinical trials. Pain Digest 1999; 9:241-247.

10. Nelemans PJ, Debie RA, DeVet HC, Sturmans $F$. Injection therapy for subacute and chronic benign low back pain. Spine (Phila Pa 1976) 2001; 26:501-515.

11. Koes BW, Bouter LM, van der Heijden GJ. Methodological quality of randomized clinical trials on treatment efficacy in low back pain. Spine (Phila Pa 1976) 1995; 20:228-235.

12. van Tulder MW, Suttorp M, Morton S, Bouter LM, Shekelle P. Empirical evidence of an association between internal validity and effect size in randomized controlled trials of low-back pain. Spine (Phila Pa 1976) 2009; 34:16851692.

13. van Tulder MW, Assendelft WJ, Koes BW, Bouter LM. Method guidelines for systematic reviews in the Cochrane Collaboration Back Review Group for Spinal Disorders. Spine (Phila Pa 1976) 1997;
22:2323-2330.

14. van Tulder $M$, Furlan A, Bombardier C, Bouter L; Editorial Board of the Cochrane Collaboration Back Review Group. Updated method guidelines for systematic reviews in the Cochrane Collaboration Back Review Group. Spine (Phila Pa 1976) 2003; 28:1290-1299.

15. Furlan AD, Pennick V, Bombardier C, van Tulder M. 2009 updated method guidelines for systematic reviews in the Cochrane Back Review Group. Spine (Phila Pa 1976) 2009; 34:1929-1941.

16. Shea B, Boers M, Grimshaw J, Hamel C, Bouter L. Does updating improve the methodological and reporting quality of systematic reviews? BMC Med Res Methodol 2006; 6:27.

17. Chou R, Huffman L. Evaluation and Management of Low Back Pain: Evidence Review. American Pain Society, Glenview, IL, 2009.

www.ampainsoc.org/pub/pdf/LBPEvidRev.pdf

18. Manchikanti L, Datta S, Derby R, Wolfer LR, Benyamin RM, Hirsch JA. A critical review of the American Pain Society clinical practice guidelines for interventional techniques: Part 1. Diagnostic interventions. Pain Physician 2010; 13: E141-E174.

19. Manchikanti L, Datta S, Gupta S, Mung- 
lani R, Bryce DA, Ward SP, Benyamin RM, Sharma ML, Helm II S, Fellows B, Hirsch JA. A critical review of the American Pain Society clinical practice guidelines for interventional techniques: Part 2. Therapeutic interventions. Pain Physician 2010; 13:E215-E264.

20. Rubinstein SM, van Tulder M. A best-evidence review of diagnostic procedures for neck and low-back pain. Best Pract Res Clin Rheumatol 2008; 22:471-482.

21. Mathews JA, Mills SB, Jenkins VM, Grimes SM, Morkel MJ, Mathews W, Scott CM, Sittampalam Y. Back pain and sciatica: Controlled trials of manipulation, traction, sclerosant and epidural injection. Br J Rheumatol 1987; 26:416-423.

22. Staal JB, de Bie RA, de Vet HC, Hildebrandt J, Nelemans P. Injection therapy for subacute and chronic low back pain: An updated Cochrane review. Spine (Phila Pa 1976) 2009; 34:49-59.

23. Manchikanti L, Rivera JJ, Pampati V, Damron KS, McManus CD, Brandon $D E$, Wilson SR. One day lumbar epidural adhesiolysis and hypertonic saline neurolysis in treatment of chronic low back pain: A randomized, double-blind trial. Pain Physician 2004; 7:177-186.

24. Dashfield AK, Taylor MB, Cleaver JS, Farrow D. Comparison of caudal steroid epidural with targeted steroid placement during spinal endoscopy for chronic sciatica: A prospective, randomized, double-blind trial. $\mathrm{Br} / \mathrm{An}$ aesth 2005; 94:514-559.

25. Ackerman WE 3rd, Ahmad M. The efficacy of lumbar epidural steroid injections in patients with lumbar disc herniations. Anesth Analg 2007; 104:12171222.

26. Zahaar MS. The value of caudal epidural steroids in the treatment of lumbar neural compression syndromes. J Neurol Orthop Med Surg 1991; 12:181-184.

27. Manchikanti L, Boswell MV, Rivera JJ, Pampati V, Damron KS, McManus CD, Brandon DE, Wilson SR. A randomized, controlled trial of spinal endoscopic adhesiolysis in chronic refractory low back and lower extremity pain. $B M C$ Anesthesiol 2005; 5:10.

28. Manchikanti L, Singh V, Derby R, Schultz DM, Benyamin RM, Prager JP, Hirsch JA. Reassessment of evidence synthesis of occupational medicine practice guidelines for interventional pain management. Pain Physician 2008; 11:393482.
29. Tekin I, Mirzai H, Ok G, Erbuyun K, Vatansever D. A comparison of conventional and pulsed radiofrequency denervation in the treatment of chronic facet joint pain. Clin J Pain 2007; 23:524-529.

30. Datta S, Lee M, Falco FJE, Bryce DA, Hayek SM. Systematic assessment of diagnostic accuracy and therapeutic utility of lumbar facet joint interventions. Pain Physician 2009; 12:437460.

31. Nath S, Nath C, Pettersson K. Percutaneous lumbar zygapophysial (facet) joint neurotomy using radiofrequency current, in the management of chronic low back pain. (Phila Pa 1976) 2008; 33:1291-1297.

32. Bogduk N. Point of View. Spine (Phila Pa 1976) 2008; 33:1298.

33. van Wijk RM, Geurts JW, Wynne HJ, Hammink E, Buskens E, Lousberg R, Knape JT, Groen GJ. Radiofrequency denervation of lumbar facet joints in the treatment of chronic low back pain: A randomized, double-blind, sham lesion-controlled trial. Clin J Pain 2005; 21:335-344.

34. Leclaire R, Fortin L, Lambert R, Bergeron YM, Rossignol M. Radiofrequency facet joint denervation in the treatment of low back pain: A placebo-controlled clinical trial to assess efficacy. Spine (Phila Pa 1976) 2001; 26:1411-1416.

35. Gallagher J, Petriccione Di Vadi PL, Wedley JR, Hamann W, Ryan P, Chikanza I, Kirkham B, Price R, Watson MS, Grahame R, Wood S. Radiofrequency facet joint denervation in the treatment of low back pain: A prospective controlled double-blind study to assess its efficacy. Pain Clinic 1994; 7:193-198.

36. van Kleef M, Barendse GAM, Kessels A, Voets HM, Weber WE, de Lange S. Randomized trial of radiofrequency lumbar facet denervation for chronic low back pain. Spine (Phila Pa 1976) 1999; 24:1937-1942.

37. Sanders M, Zuurmond WWA. Percutaneous intraarticular lumbar facet joint denervation in the treatment of low back pain: A comparison with percutaneous extra-articular lumbar facet denervation Pain Clinic 1999; 11:329-335.

38. Gauci C. Radiofrequency neurotomy for chronic lumbar facet pain - interpreting the evidence. Pain Pract 2010; 10:261.

39. Leclaire R, Bergeron Y, Lambert R, Rossignol $M$. In response to: Radiofrequency neurotomy for chronic lumbar facet pain - interpreting the evidence. Pain Pract 2010; 10:261-262.

40. Bogduk N, Dreyfuss P, Govind J. A narrative review of lumbar medial branch neurotomy for the treatment of back pain. Pain Med 2009; 10:1035-1045.

41. Carette S, Leclaire R, Marcoux S, Morin F, Blaise GA, St-Pierre A, Truchon R, Parent $F$, Levesque J, Bergeron V, Montminy $P$, Blanchette $C$. Epidural corticosteroid injections for sciatica due to herniated nucleus pulposus. N Engl I Med 1997; 336:1634-1640.

42. van Wijk RM, Geurts JW, Lousberg R, Wynne HJ, Hammink E, Knape JT, Groen GJ. Psychological predictors of substantial pain reduction after minimally invasive radiofrequency and injection treatments for chronic low back pain. Pain Med 2008; 9:212-221.

43. Pampati S, Cash KA, Manchikanti L. Accuracy of diagnostic lumbar facet joint nerve blocks: A 2-year follow-up of 152 patients diagnosed with controlled diagnostic blocks. Pain Physician 2009; 12:855-866.

44. Manchikanti L, Pampati S, Cash KA. Making sense of accuracy of diagnostic lumbar facet joint nerve blocks: An assessment of implications of $50 \%$ relief, $80 \%$ relief, single block or controlled diagnostic blocks. Pain Physician 2010; 13:133-143.

45. Cohen SP, Williams KA, Kurihara C, Nguyen C, Shields C, Kim P, Griffith SR, Larkin TM, Crooks M, Williams N, Morlando B, Strassels SA. Multicenter, randomized, comparative cost-effectiveness study comparing 0,1 , and 2 diagnostic medial branch (facet joint nerve) block treatment paradigms before lumbar facet radiofrequency denervation. Anesthesiology 2010; 113:395-405.

46. Birkenmaier C, Veihelmann A, Trouillier $\mathrm{HH}$, Hausdorf J, von Schulze Pellengahr C. Medial branch blocks versus pericapsular blocks in selecting patients for percutaneous cryodenervation of lumbar facet joints. Reg Anesth Pain Med 2007; 32:27-33.

47. Geers AL, Wellman JA, Fowler SL, Helfer SG, France CR. Dispositional optimism predicts placebo analgesia. I Pain 2010; 11:1165-1171.

48. Manchikanti L, Pampati V, Damron KS. The role of placebo and nocebo effects of perioperative administration of sedatives and opioids in interventional pain management. Pain Physician 2005; 8:349-355. 
49. Giordano J, Boswell MV. Pain, placebo, and nocebo: Epistemic, ethical, and practical issues. Pain Physician 2005; 8:331-333.

50. Vase L, Petersen GL, Riley JL 3rd, Price DD. Factors contributing to large analgesic effects in placebo mechanism studies conducted between 2002 and 2007. Pain 2009; 145:36-44.

51. Scheier MF, Mathews KA, Owens JF, Magovem GJ, Lefebvre RC, Abbott RA, Caver CS. Dispositional optimism and recovery from coronary artery bypass surgery: The beneficial effects on physical and psychological well-being. Pers Soc Psychol 1989; 57:1024-1040.

52. Isaacowitz DM. The gaze of the optimist. Pers Soc Psychol Bull 2005; 31:407-415.

53. Karademas EC, Konstantinos K, Sideridis GD. Optimism, self-efficacy, and information processing of threatand well-being-related stimuli. Stress Health 2007; 23:285-294.

54. Segerstrom SC. Optimism and attentional bias for negative and positive stimuli. Pers Soc Psychol Bull 2001; 27:1334-1343.

55. Geers AL, Handley IM, McLarney AR. Discerning the role of optimism in persuasion: The valence-enhancement hypothesis. J Pers Soc Psychol 2003; 85:554-565.

56. Pham Dang C, Lelong A, Guilley J, Nguyen JM, Volteau C, Venet G, Perrier C, Lejus C, Blanloeil Y. Effect on neuro- stimulation of injectates used for perineural space expansion before placement of a stimulating catheter: Normal saline versus dextrose $5 \%$ in water. Reg Anesth Pain Med 2009; 34:398-403.

57. Tsui BC, Kropelin B, Ganapathy S, Finucane B. Dextrose $5 \%$ in water: Fluid medium maintaining electrical stimulation of peripheral nerve during stimulating catheter placement. Acta Anaesthesiol Scand 2005; 49:1562-1565.

58. Indahl A, Kaigle AM, Reikeräs O, Holm $\mathrm{SH}$. Interaction between the porcine lumbar intervertebral disc, zygapophysial joints, and paraspinal muscles. Spine (Phila Pa 1976) 1997; 22:28342840.

59. Indahl A, Kaigle A, Reikerås O, Holm $\mathrm{S}$. Electromyographic response of the porcine multifidus musculature after nerve stimulation. Spine (Phila $\mathrm{Pa}$ 1976) 1995; 20:2652-2658.

6o. Gupta AK, Mital VK, Azmi RU. Observations of the management of lumbosciatic syndromes (sciatica) by epidural saline. J Indian Med Assoc 1970; 54:194-196.

61. Pasqualucci A, Varrassi G, Braschi A, Peduto VA, Brunelli A, Marinangeli $F$, Gori F, Colò F, Paladín A, Mojoli F. Epidural local anesthetic plus corticosteroid for the treatment of cervical brachial radicular pain: Single injection verus continuous infusion. Clin J Pain 2007; 23:551-557.
62. Pasqualucci A. Experimental and clinical studies about the preemptive analgesia with local anesthetics. Possible reasons of the failure. Minerva Anestesiol 1998; 64:445-457.

63. Arner S, Lindblom U, Meyerson BA, Molander $\mathrm{C}$. Prolonged relief of neuralgia after regional anesthetic block. A call for further experimental and systematic clinical studies. Pain 1990; 43:287297.

64. Lavoie PA, Khazen T, Filion PR. Mechanisms of the inhibition of fast axonal transport by local anesthetics. Neuropharmacology 1989; 28:175-181.

65. Bisby MA. Inhibition of axonal transport in nerves chronically treated with local anesthetics. Exp Neurol 1975; 47:481-489.

66. Cassuto J, Sinclair R, Bonderovic M. Anti-inflammatory properties of local anesthetics and their present and potential clinical implications. Acta Anaesthesiol Scand 2006; 50:265-282.

67. Manchikanti L. Interventional pain management: Past, present, and future. The Prithvi Raj lecture: Presented at the 4th World Congress-World Institute of Pain, Budapest, 2007. Pain Pract 2007; 7:357-371.

68. Sato C, Sakai A, Ikeda Y, Suzuki H, Sakamoto A. The prolonged analgesic effect of epidural ropivacaine in a rat model of neuropathic pain. Anesth Analg 2008; 106:313-320. 